\title{
GRENSE VIR DIE TAALWETENSKAP AAN DIE HAND VAN 'N GEGEWE RAAMWERK
}

\author{
P.S. de Bruyn, Dept. Afrikaans-Nederlands, PU vir CHO
}

\section{ABSTRACT}

In order to study a subject with all its facets will imply, in liguistics, that contexts also have to be taken into account. In order to give a full account of language as a means of communication one also has to pay attention to the use of language. This has the result that the language (speech) act has to be studied carefully by the linguist, because it involves the correlation among speaker, auditor and utterance in language-in-usage.

Daar word vertrek van die volgende definisie van Duvenage (1981: 29) om te probeer vasstel waar en, indien wel, hoe grense vir die taalwetenskap aan te dui is:

"' 'n Christelike wetenskap is die resultaat van die ken- en denk-aktiwiteit van die Christenwetenskaplike wat in verbondenheid aan sy geloof in God Drieenig en sy Woord hom met behulp van gepaste metodes rig op 'n bepaalde ondersoekgebied as onderdeel van die skeppingswerklikheid, met die doel om te kom tot ' $n$ algeronde, gefundeerde, sistem atiese en betroubare geheel van kennis wat die ondersoekgebied in sy konteks met die hele skeppingswerklikheid beskryf, verst aan en verklaar, en wat aan die beheersing van die skepping diensbaar is".

Die definisie is omvangryk en betrek baie komponente. Slegs enkeles daarvan word hier op die voorgrond geplaas en as vertrekpunt gebruik. Die res daarvan bly belangrik maar word nie hier pertinent in die kalklig geplaas nie. Die aandag word hier toegepits op die wetenskaplike met sy oortuiging en sy denkraamwerke, so ver as die ondersoekgebied binne die konteks van die groter werklikheid val.

As daar na denkraamwerke vir die taalkunde gekyk word, is die TGG onder andere baie prominent. Dit is algemene kennis dat die TGG verskeie aanpassings gemaak het om 'n geskikte plek vir die semantiese komponent te vind. Dit is ' $n$ wysiging waarvoor daar begrip is. Selfs Chomsky (1977: 102) sê. ". . . we should like the syntactic tramework of the language that is isolated and exhibited by the grammar to be able to support semantic description, and we shall naturally rate more highly a theory of formal structure that leads to grammars that meet this requirement more fully".

Koers, 48(2) 1983 


\section{Grense vir Taalwetenskap}

Die vraag wat mens jou moet afvra, is of enige beskrywing van taal wat hom nie ook met betekenis bemoei nie, volledig is. Deur betekenis by te bring word daar nader gekom aan die totale werklikheid. As daarna gestreef word om die mens, ook ten opsigte van sy taal, volledig te ken, is dit onvermydelik dat daar gekyk sal word na kontekste waarin die taal voorkom. Dit beteken dat as daar onder andere op die verhouding van spreker teenoor hoorder (gebruiker téenoor interpreteerder) ingegaan word, die wyse en besonderhede van die kommunikasie ook aandag moet kry.

Die term gebruiker word met opset hier ingebring, want nou kom die term gebruik ter sprake, en dit voer die saak wat betekenis betref, 'n trap verder en sny die terrein van die pragmatiek onder andere aan - hierop word later teruggekom.

Die mikrovlak ( $v g l$. Duvenage, 1981: 30) onderskei vir die taalkunde 'n aantal studieterreine, waaronder die fonetiek en fonologie, morfologie en sintaksis. Dit is egter veral die semantiek en wat daarmee saamhang wat hier onder die loep kom. Dit sou gerieflik wees om te sê dat die grens van die taalkunde duskant die semantiek getrek moet word, sodat die semantiek nie deel van die grammatika van 'n taal moet wees nie. Om die semantiek as deel van die grammatika te beskou moet daar dus sekere motivering wees (vgl. Akmajian e.a. 1979: 228 e.v.). In die taalkunde word die semantiek oor die algemeen beskou as die studie van betekenis in taal, terwyl dit in die logika beskou word as die studie van verwysing in die taal. Die verskil is eintlik slegs met betrekking tot nadruk: op die lang duur moet 'n geskikte semantiese beskrywing van natuurlike taal beide feite van betekenis en feite van verwysing opteken. Wat beantwoord moet word, is watter feite van betekenis en watter feite van verwysing vir die semantiek van belang is. Dit gaan om wat betekenis is en wat verwysing is en hoe die teorieë van betekenis en verwysing lyk.

Hierdie vrae, en veral die antwoorde daarop, voer mens dieper in die semantiek in. Dit is egter só dat die semantiek nie so maklik as die fonologie en sintaksis afgebaken kan word nie.

Die semantiek was nie altyd prominent in die moderne linguistiek nie. Argumente wat aangevoer word om semantiek as deel van die grammatika te beskou, is dat as grammatika die kennis beskryf van iemand wat sy taal vlot praat (sy linguistiese vermoë - 'competence'), dan is alles wat so 'n spreker van sy taal weet, 'n volwaardige deel van die beskrywing van daardie taal. As dit die geval is, is dit maklik om die beskrywing van betekenis as ' $n$ essensiële deel van die beskrywing van 'n spreker se linguistieke kennis te beskou. Dit kan soos volg toegelig word: 


\section{De Bruyn}

1.1 Die volgorde van klanke in sak het betekenis maar ksa nie.

1.2 Die volgorde van die woorde hout die kap het nie beteknis nie maar kap die hout wel.

1.3 Die woorde bank en vlieg is meerduidig.

Van iemand wat die feite in $1.1-1.3$ nie weet nie, sou nie gesê kan word dat hy vlot Afrikaans praat nie, omdat hy nie eens in staat sou wees om tussen betekenlose en betekenisvolle klankvolgordes te onderskei nie. Daarom moet die beskrywing van ' $n$ taal ' $n$ komponent bevat van wat sprekers van die semantiek van hulle taal behoort te weet. As die kennis wat iemand (wat sy taal vlot praat) oor sy taal het, as motivering tel om fonologiese en sintaktiese feite in die grammatika van daardie taal in te sluit, dan moet dieselfde oorweging die insluiting van semantiese feite in die grammatika van daardie taal motiveer

'n Algemener oorweging kan ook as motivering dien om die semantiese in die grammatika van 'n taal in 'a sluit: taal word dikwels gedefinieer as 'n konvensionele kommunikariestelsel, 'n stelsel om boodskappe oor te dra. Hierdie kommunikasie kan slegs slaag omdat sekere klanke of vorms sekere betekenisse het. Om hierdie stelstel (taal) te karakteriseer sal dit nodig wees om hierdie betekenisse te beskryf. Dit is die rede waarom dat as 'n grammatika ' $n$ taal beskryf, ' $n$ deel daarvan beteken is moet beskryt, en daarom moet dit ook semantiek bevat.

Sonder verdere oorwegings word dit as redelik aanvaar dat semantiese inligting deel van 'n grammatika is.

Sodra aanvaar word dat 'n semantiese teorie sekere feite het om te beskryf, moet bepaal word watter feite dit is.

Watter soort inligting staan in die middelpunt vir die beskrywing van die semantiek van 'n taal? Omdat in die semantiek die besluit om ' $n$ sekere verskynsel in die bestek van die betrokke teorie in te sluit die hele karakter van die teorie sal beinvloed, word na 'n enkele verskynsel gekyk wat normaalweg as semantiek beskou word.

\section{BETEKENIS}

In Afrikaans kan die woord beteken op 'n aantal wyses gebruik word:

2.1 Die prestasie beteken iets (het warde).

2.2 Die optrede van die regering beteken volle burgerskap vir almal (sal die resultaat hê). 


\section{Grense vir Taalwetenskap}

2.3 Sonder reëlmaat beteken oefening niks (is die gevolg).

2.4 Bly van die gras af: dit beteken jy (verwys na).

2.5 Hy het sy werk verloor en dit beteken hy sal moet gaan soek (impliseer).

2.6 Lexington beteken jy hoes jou dood (het die gevolg).

2.7 Wolke beteken reën (is 'n teken van).

2.8 Sloer beteken om dinge uit te stel.

2.9 Wat hy gesê het, het beteken dat ons moet toop.

Omdat elkeen van die gebruike behalwe 2.8 en 2.9 met ander woorde as beteken geparafraseer kan word, word betekenis gereserveer vir die twee gevalle wat nou die twee belangrike soorte betekenis tipeer, naamlik sprekerbetekenis en liguistiese betekenis.

\section{SPREKERBETEKENIS EN LINGUISTIESE BETEKENIS}

Sprekerbetekenis (bedoeling) stem met linguistiese betekenis ooreen in sover as die spreker letterlik praat. By nie-letterlike spraak bedoel die spreker iets anders as wat die woorde beteken. Die nie-letterlike maniere waarop'n mens kan praat, is bv. skertsend (ironies of sarkasties), waarby die teenoorgestelde bedoel kan word van wat gesê word. So kan mens ook byvoorbeeld oordryf of metafories praat. Sprekerbetekenis kom later uitdrukliker ter sprake - dit word hier genoem, hoofsaaklik om dit apart te hou.

Dit is duidelik dat 'n grammatika van 'n taal nie kan voorspel wanneer sprekers nie-letterlik sal praat nie, dit wil sê met hulle woorde nie bedoel wat dit in die taal beteken nie. Dit sou met ander woorde moeilik bereëlbaar wees.

Oor die algemeen gesproke is die linguistiese betekenis van 'n uitdrukking bloot die betekenis of betekenisse van daurdie uitdrukking in die een of ander vorm van die taal. So $k a n$ daar 'n verskil wees in die betekenis van 'n uitdrukking in die standaardtaal teenoor een of ander dialek of idiolek. Vergelyk die woord kwaad in die volgende sinne:

3.1 Die man is kwaad vir sy kinders.

3.2 Daar het kwaad in die wond gekom.

3.3 Die meisie is ' $n$ regte kwaad kat. 


\section{De Bruyn}

Vergelyk ook blare in die volgende:

3.4 Die boom verloor sy blare.

3.j Daar is blare /blase in sy hande van die harde werk.

3.6 Jy skuld my 'n honderd blare /skille vir die werk.

Die volgende figuur (vergelyk Akmajian, 1979: 232) behoort die verwikkeldheid van betekenis as sodanig te illustreer:

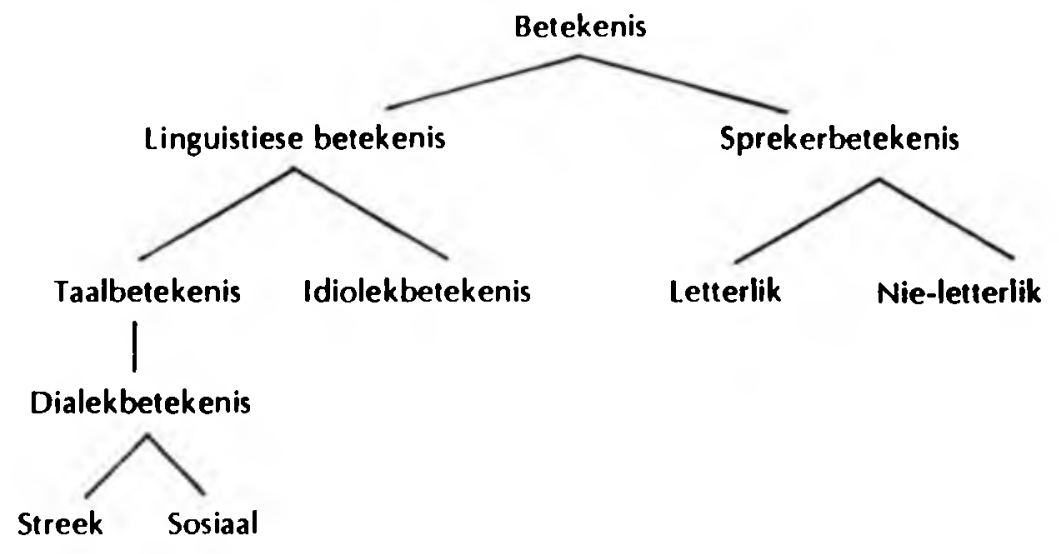

Hier word nie verder op die vereistes vir 'n geskikte semantiese teorie van 'n taal ingegaan nie, maar daar word gekyk na die sogenaamde sprekerbetekenis en so geprobeer om nader te kom aan betekenis-in-gebruik. Die volgende kry nie hier aandag nie: die verwysingsteorie, wat kan lui:

Die betekenis van elke uitdrukking is die werklike voorwerp waarna dit verwys, sy referent. So word hier ook nie aan die mentalistiese teorie van betekenis aandag gegee nie:

Die betekenis van elke uitdrukking is ' $n$ idee geassosieer met die uitdrukking in die denke van sprekers.

Dit wil voorkom of sprekerbetekenis tuis hoort by die teorie van betekenisin-gebruik, wat neerkom op:

Die betekenis van 'n uitdrukking word deur sy gebruik in die taalgemeenskap bepaal. 
Die hoofprobleetn mot die teorie betekenis-in-gehruik is dat die tersaaklike begrip van gebruik gepresiseer moel word en die Irorie moet noukrurig adndui hoe betekenis met gebruik verbind is.

Al wil dit voorkom asof die saak oor wat kommunikasic is, nog lank nie afgeshuit is nie, word vervolgens nader ingegaan op laalgebruik en linguistiese kommunikasic soos dit onder die term pragmatick saamgevat word.

Hier word dic aandag bepaal by dir gebruik van taal as instrument tot menslike kommunikasie. Spraak is een van die algemeenste kenmerke van menslike interaksie, maar waarom sou 'n taalkundige hom met taalgebruik bemoei as hy 'n taal beskry? Presies wal is hierdie verskillende gebruike van taal, veral die in die middelpunt on kummunikasic? Sulke vrae dien as inleiding (o) pragmatiek as onderwerp en 'n poging om dil met ' $n$ informele teorie te beantwoord voltooi daardie inleiding.

Die rede om pragmatiese inligting in 'n grammatika in te sluit, sluit by die semantick aan. Daar is reeds die opvalting dat taslgebruik die basis vir semantick sal verskaf: dus sal die deel van die prapmatick wat hom met becekenis en verwysing bemoei, ded van 'n grammalika wees.

'n Tweede rede vir die insluiting van pragmatiese inligting in 'n grammatika is om die linguistiese vermoë ('competence') van 'n vaardige spreker na le gaan. As 'n spreker nie die volgende inligting ken nie, sou hy nic as 'n valdige spreker beskou kan word nie:

4.1 Ilallo word gebruik oin te groet.

4.2 Tot siens word gebruik om afskeid te neem.

4.3 Die frase daardic tafel kan deur 'n spreker gebruik word om na 'n spesifieke tafel te verwys.

4.4 Die frase ' $n$ lafel kan deur spreker gebruik om na enige tafel le verwys.

4.5 Suiker, asseblief word gebruik om sekere suiker te vra.

4.6 Iloc oud is jy? word gebruik om na iemand se ouderdom te vra.

4.7 Wat maak mens as iy by 'n kamer inkom? word gebruik om iennand te vra om 'n drur toe te maak.

4.8 (Fk belowe) ek sal daar wres word gebruik om te belowe, ens.

Wat is die doelstellings van en die bewering wat die pragınatick maak? 


\section{De Bruyn}

Om die vriag in beantworırd mont daar onderskei word tussen die gebruik van tad om iess re dorn en die grobruik van tal in die doen van iets. As gekyk word na wat mens mel ldal doen, kom dit wat mens in 'n besondere siluasio men wororde doen. onder die soeklig: daar word toegespits of die bedoelings, voorne:mens, gelowe en l,rgecertes van' 'n speeker as hy praat - as hy taslhandelinge uitvoer ('sperech acks). Die sludie vill taalhandelinge word as die hoofsalak van die pragmatiek beskou, en daarom word daarop gekonsentreer en later net verwys na die ander terreine wat nou by die pragmatiek ansluil, sondor om in besonderhede daarop in te gaan.

As na die geloruik van taal gekyk word, betcken dit dan (hoofsaaklik) die kalegorisering van die aard en verskeidenheid van Ialhandelinge.

\section{IIPES TAALHANDELINGE}

Diegene wall oor thalhandelinge teoreliseer, maak gebruik van Austin se terminologie:, wat verder deur Searle in 'n uitvocrige bespreking bevestig is. Die verdeling van tadhandeling in onderafdelings kan soos volg geillustreer word:

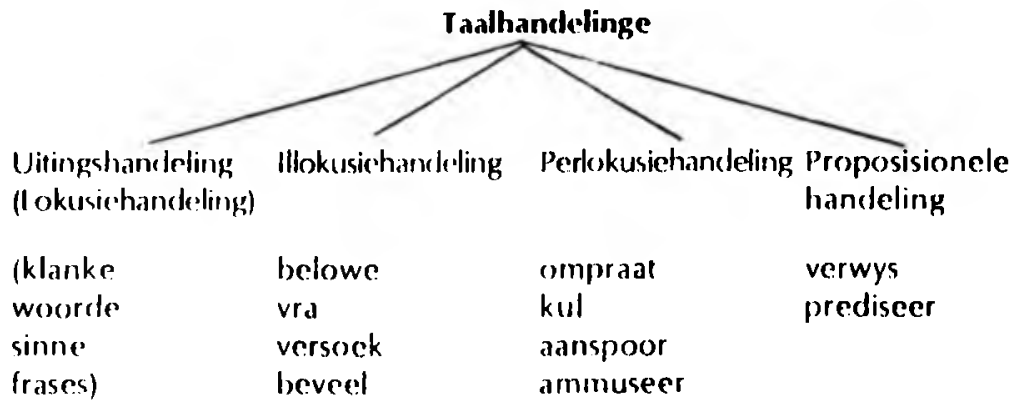

Uitingshandelinge (lokusirhandelir:ge) dui bloot op die uiting van klanke, sillabes, woorde, frases en sinne van' $n$ laal. Ondat die uitingshandeling op sigsell nie kommunikatiel is nie, is dit uit die oogpunt van die taalhandeling nie baie interessant nie - dil kan deur 'n bandopname, 'n papegaai ens. uirgevoer word. Die hoofbelangslelling in uitingshandeling is daarin dat in die uitvoering daarvan 'n illokusichandteling en/of 'n perlokusichandeling gevit word. 'n Illokusiehandeling is 'n handeling wat in die uiting van iets uitgevoer word, en 'n handeling wat 'n rflek by dic: hoorder veroorsaak. 


\section{Grense vir Taalwetenskap}

Voorbeelde van illokusiehandelinge kan wees:

bedank

belowe

vertel

rapporteer ens.

'n Belangrike kenmerk van 'n illokusiehandeling is dat dit uitgevoer kan word deur slegs die korrekte eksplisiete performatiewe sin te uit, mel die korrekte bedoelings en geloof en in die korrekte situasie. Die volgende sinne voer die illokusiehandeling van beveel, belowge en voorspel respektiewelik uil:

5.1 Ek beveel jou (hiermee) om te speel.

5.2 Ek belowe jou (hiermee) ek gaan jou help.

5.3 Ek voorspel (hiermee) dat dit gaan reën.

'n Volgende kenmerk van illokusiehandelinge (anders as perlokusiehandelinge) is dat dit in die middelpunt van linguistiese kommunikasie is. Enige normale gesprek is in 'n groot mate saamgestel uit stellings, suggesties, versoeke, voorstelle, begroetings ens. As mens wel perlokusiehandelinge uitvoer, soos byvoorbeeld om te oortuig of te intimideer, doen jy dit deur illokusiehandelinge soos stellings of dreigemente uit te voer.

'n Ander en baie belangrike kenmerk is dat die meeste illokusiehandelinge (anders as perlokusiehandelige) wat vir kommunikasie gebruik word, met welslae uitgevoer $k$ an word deurdat mens slegs die illokusionêre bedoeling herken. As ek byvoorbeeld sou sê

\section{Abott is 'n aap}

en my hoorder sou daardeur bewus word dat ek aan hom probeer sê dat Abott 'n swak bokser is, het ek daarin geslaag om dit oor te dra, en my hoorder het my verstaan. As ek egter probeer om daarmee my hoorder le oortuig dat Abott ' $n$ swak bokser is, is dit nie voldoende dat my hoorder daarvan bewus word nie: hy moet ook glo dat Abott swak is. My hoorder sal die bedoeling herken maar sal nie noodwendig daarvan oortuig wees nie.

Perlokusiehandeling word getipeer as handelinge wat uitgevoer word deur iets te sê. Veronderstel $A$ sou alles glo wat $B$ sê, dan sou ' $n$ uiting soos

Abott is 'n aap 
De Bruyn

$\operatorname{deur}$ A B oortuig dat Abott 'n swak bokser is. Ander voorbeelde van perlokusiehandelinge is:

ompraat

kul

aanspoor

ammuseer

irriteer

inspireer

verveel

ens.

Belangrike kenmerke van perlokusiehandelinge is dat hulle (anders as illokusiehandelinge) nie uitgevoer word deur eksplisiete performatiewe sinne te uit nie. Die perlokusiehandeling byvoorbeeld om te oortuig word nie uitgevoer nie deur 'n uiting soos:

- Ek oortuig jou (hiermee) dat Abott 'n swak bokser is.

Dit is verder duidelik dat perlokusiehandelinge te doen het met die resultaat, die effek van uitingshandelinge en illokusiehandelinge op die gedagtes, gevoelens en optredes van die hoorder. So kan perlokusiehandelinge voorgestel word as ' $n$ illokusiehandelinge van die spreker (S) plus die uitwerking daarvan op die hoorder $(\mathrm{H})$.

6. $S$ vertel $+\mathbf{H}$ glo $\ldots=$ S oortuig $H$ dat ...

As daar weer gekyk word na illokusiehandelinge soos bewering, vraag en versoek, sal opgemerk word dat daar 'n oorvleueling kan wees van wat beweer, bevraagteken en versoek word. Vergelyk die volgende uitings:

7.1 Abott klop Coetzee (stelling)

7.2 Abolt klop Coetzee? (vraag)

7.3 Abolt, klop Coetzeel (bevel/versoek)

Aldrie bestaande illokusiehandeling het te doen met Abott wat Coetzee klop, en dit word die proposisionele inhoud van die illokusiehandeling genoem. Soos in 7 geillustreer, kan verskillende soorte illokusiehandelinge dieselfde proposionele inhoud he. 


\section{Grense vir Taalwetenskap}

Die eenvoudigste soort proposionele inhoud word uitgedruk deur handelinge van verwysing en predikasie, waar 'n spreker na iets verwys en dit dan karakteriseer: as 'n spreker sou sê

\section{Abott is moeg,}

poneer hy daarmee die stelling dat Abott moeg is. In die ponering van die stelling voer die spreker ook die proposisionelehandelinge uit van verwysing na Abott met die naam Abott en die karakterisering van hom met die predikaat is moeg.

Die vier hooftipes taalhandelinge is hiermee geskets: die uitingshandeling (lokusiehandeling), die illokusiehandelinge, die perlokusiehandeling en die proposisionele handelinge. Hierdie handelinge sou in interessante onderafdelings en op verskeie wyses verdeel kan word. Dit word egter nie hier gedoen nie.

Onderafdelings en aanverwante sake waarop daar veel gesê is en nog veel gesê kan word, is die voorkoms van die performatief, eksplisiete en implisiete taalhandelinge, die verwantskap van die implisiete performatief met die perlokusiehandelinge, gesprekvoorwaardes, implikasie en vooronderstellings.

Dit is uit dit alles duidelik dat die pragmatiek nie maklik met idealisering kan werk nie - dit gaan juis in op die ingewikkeldheid / die kompleksiteit van 'n werklike situasie. Idealisering het die waarde dat daaromheen ander teorieë in verband met werklike situasies gevorm kan word. Idealisering kan as ' brandpunt beskou word van 'n navorsingsprogram wat uiteindelik tot 'n sistematiese en bygewerkte teorie kan lei. 'n Teorie van idealisering moet beskou word as die plek waar alle linguiste mekaar behoort te ontmoet om die eenheid van die dissipline te bewaar, en nie die plek waar hulle van mekaar moet wegbreek nie.

Met die semantiek en die pragmatiek skuif die grense van die taalkunde uit na plekke wat nog nie duidelik is nie - dat daar 'n ontsaglike studie voorlê om dit te bepaal, is seker.

Perlokusiehandeling word gesien as die terrein waar daar in die toekoms nog baie oor gesê gaan word - dit is waarskynlik die plek waar die taalkundige en die letterkundige die naaste aan mekaar gaan kom. 


\section{De Bruyn}

\section{BIBLIOGRAFIE}

AKMAIIAN, A. e.a. reds. 1979. Linguistics. An introduction to language and communication. Ney York MIT Press.

CHOMSKY, N. 1972. Synlactic Structures. Den Haag: Mouton.

DE BRUYN, P.S. 1979. Buitesintaktiese faktore in die semantiek van oppervlaktestrukture in Afrikaans. (Ongepubliseerde D.Litt.-tesis. U P).

DUVENAGE, B. 1981. Roeping en wetenskap. Potchefstroom: Pro Rege.

SEARLE, J.R. 1974. Speech acts. An essay in the Philosophy of Language. Cambridge : University Press.

SEARLE. J.R. e.a. reds. 1980. Speech act theory and pragmatics. New York : Reidel.

URMSON, J.O. en SBISA, M. 1976. J.L. Austin. How to do things with words. Oxford : University Press. 